\title{
Fonte investigadora em Educação: registros do banco de teses da CAPES
}

Renata de Almeida Vieira

Lizete Shizue Bomura Maciel

Universidade Estadual de Maringá

\section{Resumo}

Apresenta-se neste artigo o resultado de uma investigação realizada no Banco de Teses CAPES - Resumos, banco de dados multidisciplinar disponibilizado via internet pela Coordenação de Aperfeiçoamento de Pessoal de Nível Superior - CAPES. Ao congregar informações básicas de pesquisas de pós-graduação stricto sensu - mestrado e doutorado - das diversas áreas e subáreas do conhecimento humano, desenvolvidas em Instituições de Ensino Superior - IES - públicas e particulares de todo o território nacional e defendidas a partir de 1987, esse banco, por meio de resumos, constitui-se em uma fonte de pesquisa abrangente, bem como em um instrumento relevante de divulgação do conhecimento científico brasileiro. Considerada tal abrangência e relevância, ao perceber em consulta às suas bases algumas incongruências nos dados recuperados pelo sistema, bem como falta de informações senão importantes, mas efetivamente necessárias àqueles que pesquisam ou buscam informações preliminares de estudos, efetuou-se uma investigação exploratória em uma amostra de seus registros, a qual se pautou em pesquisa documental e foi iniciada por meio da palavra-chave preconceito. Fruto dessa exploração é o presente ensaio, que tem por objetivo apresentar um panorama das constatações feitas acerca do aspecto formal dos registros e das estrutura dos resumos constantes nesse banco. Objetiva-se, também, marcar a importância de se realizar estudos que contribuam para o fomento de um debate crítico-reflexivo que implique ações resolutivas dos problemas constatados.

\section{Palavras-chave}

Banco de Teses CAPES - Fonte de Pesquisa - Resumo - Estrutura dos Resumos - Preconceito.
Correspondência:

Renata de Almeida Vieira

Rua Miguel Vieira Ferreira, 34

87020-360 - Maringá - PR

e-mail: realvieira@gmail.com 


\title{
An investigation source in education: the records in the CAPES theses database
}

Renata de Almeida Vieira

Lizete Shizue Bomura Maciel

Universidade Estadual de Maringá

\begin{abstract}
This article presents results of an investigation made with the CAPES Theses Database - Abstracts, a multidisciplinary database offered through the Internet by CAPES - Coordination for the Improvement of Higher Education Personnel. By congregating basic information about stricto sensu graduate researches Master and Doctorate levels - developed in various areas and subareas of the knowledge by Institutes of Higher Education, both private and public, from throughout the country since 1987, this database, via its abstracts, constitutes a wide-ranging research tool, and also an important instrument for the publicizing of Brazilian scientific knowledge. Considering the scope and relevance of this database, and noticing some discrepancies in the data recovered from the system, as well as some lack of information which, although perhaps not capital, were certainly necessary for those doing research or seeking preliminary information for studies, an exploratory study was developed with a sample of its records, based on documental research, and initiated through the keyword "prejudice". The present essay is a direct result of that study, and has as its main purpose to give an outline of the findings on the formal aspects of the records and structure of the abstracts. It also has as an objective to contribute to a critical-reflective debate that will promote actions toward the solution to the problems encountered.
\end{abstract}

\section{Keywords}

CAPES Theses Database - Source for research - Abstract - Structure of abstracts - Prejudice. 
Este ensaio apresenta uma visão panorâmica da produção científica, no que se refere a dissertações de mestrado e teses de doutorado, acerca do assunto preconceito, incluído no Banco de Teses CAPES - BTC Resumos entre os anos de 1987, marco de sua fundação, e 2005, ano de realização do levantamento dos dados para o estudo em tela. 0 ano dos registros mais recentes, no entanto, encontrado no BTC Resumos, foi 2003, constituindo-se este como ano final do nosso marco temporal.

O BTC Resumos é um banco de dados multidisciplinar que agrega as grandes áreas do conhecimento, suas divisões, subdivisões e especificidades. Disponibilizado pela Coordenação de Aperfeiçoamento de Pessoal de Nível Superior - CAPES $^{1}$-, em seu sítio, contém informações fornecidas pelos Programas de PósGraduação do país, aos quais é atribuída a responsabilidade pela veracidade do conteúdo cadastrado, cujo acesso é livre e possibilitado via Internet.

0 presente ensaio teve origem a partir de consultas efetuadas ao BTC Resumos em dezembro de 2005, em meio ao processo de levantamento de informações requisitado na Fase de Exploração para a elaboração do Projeto de Pesquisa ou Fase/Prática da Documentação, conforme Eco (2004) e Severino (2002). Tal levantamento possibilita, entre outras coisas, conhecer o estado da arte acerca de um determinado tema circunscrito para pesquisa. Em nosso caso, refere-se à temática do preconceito, que é um fenômeno produzido e disseminado historicamente na prática social dos homens e que, na atualidade, tem adquirido uma diversidade de aspectos que se soma a outros recrudescentes que permeiam os muitos segmentos da sociedade.

Mediante leitura de alguns cadastros do BTC Resumos, cujo padrão de organização consiste em informações básicas do trabalho (como, por exemplo, nome do orientando, título do trabalho, instituição, orientador etc.) e resumo, percebemos uma marcante inconstância no aspecto formal dos registros e a ausência de infor- mações relevantes em alguns resumos, que possibilitassem ao usuário entender o que o autor estava comunicando por meio das informações apresentadas e, por conseguinte, decidir, com certo grau de segurança, sobre a conveniência ou não de se consultar um dado trabalho na integra. Tais fatos chamaram nossa atenção.

Assim, este ensaio foi se constituindo por meio de leituras e classificações dos 139 registros de teses de doutorado e 654 registros de dissertações de mestrado apresentados pelo BTC Resumos mediante o preenchimento dos campos $\underline{\text { Assunto }}=\underline{\text { Preconceito e Nível }=\text { Mestrado } / \text { Doutorado, }}$ como de uma análise mais minuciosa dos registros da área da Educação, nosso campo de pesquisa e atuação.

Entendemos que um estudo a respeito da produção científica registrada no BTC Resumos no decorrer das quase duas décadas de sua existência, de 1987 a 2003, justifica-se por se tratar de um banco de dados abrangente, o qual concentra trabalhos de pós-graduação stricto sensu de Instituições de Ensino Superior - IES - públicas e particulares de todo o território nacional. E, ainda, por se tratar de uma fonte de pesquisa relevante, a qual abarca as diferentes áreas do conhecimento humano, o que poderia ou deveria facilitar a busca de informação e minimizar tempo e custos para seu levantamento e conhecimento pelos pesquisadores.

\section{Aspecto formal das informaçôes básicas das teses}

Para efetuar uma análise do aspecto formal das 139 teses que trazem o assunto preconceito registradas no BTC Resumos, foi preciso estipular uma ordem à consulta e coleta das informações constantes no banco de dados. Nesse sentido, optamos, primeiramente, em realizar uma

1. Criada em 1951 com o objetivo de "assegurar a existência de pessoal especializado em quantidade e qualidade suficientes para atender às necessidades dos empreendimentos públicos e privados que visam ao desenvolvimento do país", a CAPES tem como uma de suas grandes linhas de ação possibilitar o acesso e a divulgação da produção científica (CAPES, 2006). 0 BTC Resumos tem, certamente, um papel importante a desempenhar no cumprimento desse propósito. 
leitura seqüencial dos registros, numerando-os em ordem crescente a fim de identificá-los em vez de fazê-lo por meio do nome completo do autor.

Ao tomar como base a Tabela de Áreas do Conhecimento, obtida no Conselho Nacional de Desenvolvimento Científico e Tecnológico CNPq (2005), classificamos os registros das 139 teses em Grande Área e Área, excetuando seis registros constantes no BTC Resumos que ficaram sem a devida classificação por não conterem informações precisas.

As Grandes Áreas do Conhecimento, que compõem o universo dos registros de teses classificados, são: Ciências Humanas, com 72 trabaIhos; Ciências da Saúde, com 28 trabalhos; Lingüística, Letras e Artes, com 18 trabalhos; e por fim Ciências Sociais e Aplicadas, com 15 trabalhos. 0 detalhamento das áreas e a quantidade de trabalhos alocada no interior das Grandes Áreas podem ser observados no quadro abaixo:

Coletamos também, nos registros, o ano de defesa de cada tese, informação esta utili- zada, posteriormente, para classificação do ano do trabalho em um dos três Períodos de Desenvolvimento - PD -, por nós elaborados: PD1 que abrange os anos de 1987 a 1992; PD2, de 1993 a 1998; e PD3, de 1999 a 2003. Essa classificação, vale constar, foi estabelecida com base em critérios adotados pela pós-graduação no Brasil, no preenchimento de dados da DataCapes, em concursos públicos das IES para docentes, nos quais são solicitados dados e produções relativas aos últimos cinco anos. Para tal, utilizamos o mesmo intervalo de cinco anos, a partir de 1987.

Segundo a classificação, obtivemos o seguinte resultado: PD1 com 7 trabalhos registrados, fato que, ao nosso ver, pode estar relacionado com o início de funcionamento do banco de dados e, talvez, o desconhecimento de sua existência por parte de programas de pós-graduação, orientando e orientador; PD2 com 37 trabalhos; e PD3 com 95 trabalhos. Este, conforme podemos visualizar no Gráfico 1, expressa um salto considerável no número de registros.

Quadro 1: Quantidade de teses de 20 áreas do conhecimento, de acordo com o CNPq.

\begin{tabular}{|c|c|c|c|c|c|c|c|}
\hline \multicolumn{2}{|c|}{ Cilencias Humanas } & \multicolumn{2}{|c|}{ Ciências da Saúde } & \multicolumn{2}{|c|}{ Lingứstica, Letras e Artes } & \multicolumn{2}{|c|}{ Ciencias Sociais e Aplicadas } \\
\hline Áraa & $N^{*}$ & Área & $N^{*}$ & Área & $N^{*}$ & Área & $N^{a}$ \\
\hline Educaçåo & 31 & Enfermagem & 13 & Lingüistica & 8 & Serviço Social & 7 \\
\hline Psicologia & 18 & Saúde Coletive & 6 & Letras & 7 & Direto & 5 \\
\hline História & 7 & Medicina & 4 & Ntes & 3 & Comunicacáo & 3 \\
\hline Sociologia & 6 & Educacăo Fisica & 4 & & & & \\
\hline Antroodlogia & 5 & Ddantologia & 1 & & & & \\
\hline Teologia & 2 & & & & & & \\
\hline Céncia Pollica & 1 & & & & & & \\
\hline Ceografia & 1 & & & & & & \\
\hline Fiksofia & 1 & & & & & & \\
\hline Total & 72 & Totgl & 28 & Total & 18 & Total & 15 \\
\hline
\end{tabular}

Fonte: BTC Resumos [Teses] - CAPES [2005]

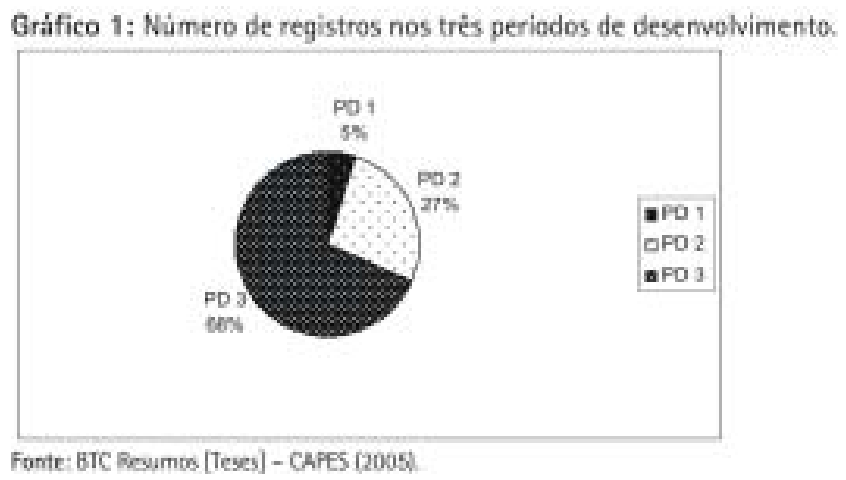


Uma outra classificação adotada foi referente à quantidade de volumes do trabalho de tese depositada nas bibliotecas das instituições ou dos programas de pós-graduação. Constatamos que, dos 139 registros, somente 8\%, isto é, 11 registros, tinham disponibilizado dois ou mais exemplares do trabalho, enquanto 92\%, isto é, 128 registros, indicavam o depósito de um único volume da tese.

Em que pese ser o Brasil um país de extensão continental e que, conforme indicamos no Gráfico 1, nos últimos anos, a quantidade de estudos vem aumentando consideravelmente, entendemos que o depósito de um único volume de uma tese pode ser insuficiente caso mais de um pesquisador esteja se dedicando ao estudo de um mesmo tema, ainda que de perspectivas diferentes e recortes específicos, e queiram coincidentemente consultar uma tese de volume único.

Classificamos também a indicação de correio eletrônico nos registros, haja vista ser essa informação, muitas vezes, imprescindivel para localização e possível consulta de uma dada tese. A classificação adotada foi: registros sem e-mail e registros com e-mail. Obtivemos a seguinte proporção: 96 trabalhos, ou 69\% dos registros, sem e-mail; e 43, isto é, 31\%, com email. Considerando que a maior parte desses trabalhos registrados no BTC Resumos foi produzida entre 1999 e 2003, entendemos que o universo de e-mails disponíveis deveria ser maior, uma vez que esse meio de comunicação tem se popularizado bastante. Ademais, entendemos que o correio eletrônico constitui-se em um canal potencialmente privilegiado de acesso às informações por meio do contato direto com o autor da tese, podendo, quiçá, constituir-se ainda em um elemento facilitador para a fase de documentação da pesquisa científica.

Uma outra classificação realizada foi referente ao financiamento das pesquisas, cujos resultados foram: 78 registros indicando financiamento, o equivalente a 56\% do total, e 61 registros sem essa indicação, isto é, 44\% dos trabalhos. A maior parte do financiamento foi oferecida pela CAPES, 47 trabalhos, seguido pelo CNPq com 24 trabalhos. Os demais financiamentos foram oferecidos por outras agências, tais como FAPERGS, FAPESP, entre outras.

Com relação aos dados sobre a IES que aloca o programa de pós-graduação e a linha de pesquisa a qual se vincula a tese, observamos que as informações são completas no que se refere à IES e ao programa, mas há quase duas dezenas de registros nos quais não constam as linhas de pesquisa, extensivamente cobradas pelos próprios programas de pós-graduação, pelas IES e pelos órgãos financiadores de pesquisa.

Ao término da classificação geral e análise acerca do aspecto formal das 139 teses, exercício esse que nos propiciou uma visão panorâmica do universo de trabalhos acerca do assunto preconceito, remetemos nossa atenção à análise dos registros da área da Educação.

Ao compulsar os registros da área da Educação, os quais somam o número de 31, constatamos que nenhum deles disponibiliza o endereço do correio eletrônico, assim como não indicam ter depositado mais de um volume do trabalho de tese, fatos que, a depender das circunstâncias, podem dificultar a consulta dos trabalhos completos.

Constatamos também que 19 trabalhos, ou $61 \%$ do total, foram financiados e 12, 39\%, não receberam financiamento algum. E ainda que apenas uma tese foi desenvolvida no período de 1987 a 1992, PD1, enquanto oito foram desenvolvidas no período correspondente ao PD2, 1993 a 1998, e a grande maioria, 22 trabalhos, no decorrer do PD3 - 1999 a 2003.

Uma informação extra que coletamos, excepcionalmente, durante as releituras dos registros da área da Educação foi sobre a constituição de gênero dos autores das teses. Observamos que 25 trabalhos, $81 \%$, foram elaborados por mulheres e $6,19 \%$, por homens. Isso se relaciona possivelmente com a presença majoritária e histórica de mulheres na área da Educação, todavia essa discussão não será privilegiada neste texto. 
Quadro 2: Quantidade de Disserteçues de 32 Áreas do Conhecimento, contorme o CNPq.

\begin{tabular}{|c|c|c|c|c|c|c|c|c|c|c|c|c|c|}
\hline \multicolumn{2}{|c|}{ Cuncias Humanas } & \multicolumn{2}{|c|}{$\begin{array}{l}\text { Ciancias Socials e } \\
\text { Aplicadas }\end{array}$} & \multicolumn{2}{|c|}{$\begin{array}{l}\text { Lingüistica, } \\
\text { Letras e } \\
\text { Artes }\end{array}$} & \multicolumn{2}{|c|}{ Ciências da Saúde } & \multicolumn{2}{|c|}{ Ciências Agrárias } & \multicolumn{2}{|l|}{ Engenharias } & \multicolumn{2}{|c|}{$\begin{array}{l}\text { Ciencias } \\
\text { Biológicas }\end{array}$} \\
\hline Área & $N^{2}$ & Área & $N^{p}$ & Area & $\mathrm{N}^{*}$ & Área & $N^{p}$ & Area & $N^{p}$ & Area & $N^{0}$ & Área & $N^{2}$ \\
\hline Eđucaçã̃o & 158 & Direito & 62 & $\begin{array}{l}\text { Lingui } \\
\text { stica }\end{array}$ & 29 & Enfermagem & 40 & $\begin{array}{l}\text { Ciancia r } \\
\text { Tecnologia. de } \\
\text { Almentos } \\
\end{array}$ & 4 & $\begin{array}{l}\text { Engenharia } \\
\text { de produç5. }\end{array}$ & 2 & Zoologia & 1 \\
\hline Psicologia & 82 & Servico Social & 19 & Lefras & 45 & Sacide Coletiva & 17 & $\begin{array}{l}\text { Medicina } \\
\text { Veterinária }\end{array}$ & 2 & $\begin{array}{l}\text { Engentheria } \\
\text { Civ }\end{array}$ & 1 & & \\
\hline História & 41 & Comunicaçăo & 19 & Arles & 5 & Mediona & 12 & Agronomia & 1 & & & & \\
\hline Socioboia & 33 & Administraça & 5 & & & Edaracajo Fisica & 7 & & & & & & \\
\hline Antropologia & 13 & \begin{tabular}{|l|} 
Arquitebura e \\
Urberismo
\end{tabular} & 5 & & & Fonnaudalogia & 1 & & & & & & \\
\hline Texloja & 11 & \begin{tabular}{|l|} 
Cência da \\
rformaçán
\end{tabular} & 2 & & & Oodontologia & 1 & & & & & & \\
\hline $\begin{array}{l}\text { Cléncia } \\
\text { Politica }\end{array}$ & 4 & Economis & 2 & & & & & & & & & & \\
\hline Geografia & 5 & Turismo & 2 & & & & & & & & & & \\
\hline Filosolia & 2 & & & & & & & & & & & & \\
\hline 7otas & 349 & Total & 116 & Total & 79 & Tatal & 78 & Tatal & 7 & Total & 3 & Total & 1 \\
\hline
\end{tabular}

Fonte: BTC Resumos [Dissertą̧6es] - CAPES (2005)-

Gráfico 2: Número de registros nos tớs periodos de desernowimento.

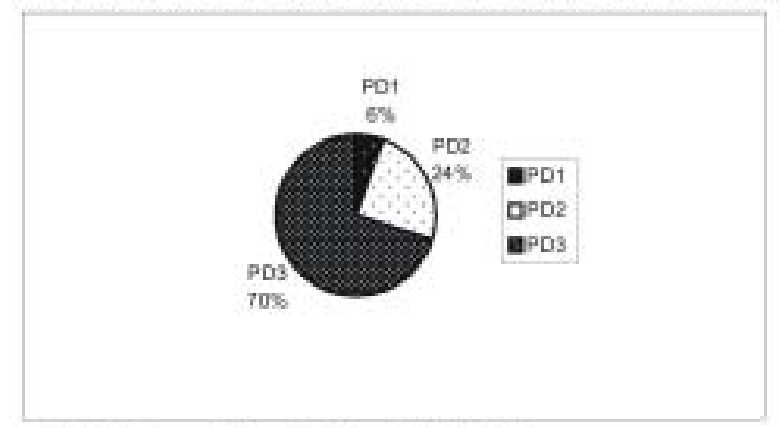

Fonte: BTC Resumas [Disserlaçōes] - CAPES (2005)

\section{Aspecto formal das informações básicas das dissertações}

Para classificação e análise das informações básicas das dissertações, procedemos de modo análogo ao trabalho realizado com as teses. Tomando-se por base o preenchimento dos campos $\underline{\text { Assunto }}=\underline{\text { Preconceito e Nivel }=\text { Mestrado }}$, bem como desconsiderando os campos Autor e Instituição, opções oferecidas pelo BTC Resumos, mas inválidas para o nosso trabalho, foi recuperado um total de 654 trabalhos registrados desde 1987.

Principiamos com uma leitura seqüencial dos registros, aos quais fomos atribuindo uma numeração em ordem crescente. De posse da Tabela de Áreas do Conhecimento (CNPq, 2005), classificamos a grande maioria dos registros, exatamente 633, em Grande Área e Área, sendo que 21 ficaram sem a devida classificação por ausência de informações claras.

Com base nos resultados, elaboramos o Quadro 2 com o detalhamento, em uma seqüência decrescente, da quantidade de trabalhos por Grandes Áreas e suas respectivas Áreas.

Com relação ao ano de defesa da dissertação, os trabalhos agrupados, em um dos três Períodos de Desenvolvimento, revelam 37 registros no PD1; 158 registros no PD2; e 459 registros no PD3. 0 resultado obtido, semelhante ao 
que ocorreu com as teses, mostra-nos um aumento marcante de trabalhos nos últimos cinco anos, conforme se observa no Gráfico 2 .

No que concerne à presença ou ausência de endereço de correio eletrônico, verificamos 445 registros sem e-mail, o equivalente a $68 \%$, e 209 com e-mail, isto é, 32\%. Quanto aos volumes do trabalho da dissertação depositados nas bibliotecas das IES ou dos programas de pós-graduação, constatamos que 603 registros, 92\%, indicam depósito de um único volume. Em contrapartida, há 51 registros, $8 \%$, que indicam o depósito de dois volumes ou mais.

A formação dos mestrandos foi, de acordo com os registros, financiada em 276 trabalhos, ou seja, 42\%, enquanto 378 trabalhos não mencionam nenhum tipo de financiamento, o que equivale a 58\% do total. Referente aos dados sobre as IES, os programas de pósgraduação e as linhas de pesquisa, houve reincidência do resultado obtido com as teses, qual seja, ausência de informações quanto ao último item em 53 registros.

Empreendemos, também, uma classificação quanto ao preenchimento parcial/total das informações básicas contidas nos 654 registros. Para tanto, ordenamos os trabalhos em três grupos: Grupo 1: recebeu os registros que apresentavam ausência de duas ou mais informações; Grupo 2: registros que apresentavam ausência de apenas uma informação; e Grupo 3: registros que continham informações completas ${ }^{2}$.

Após a ordenação dos registros, obtivemos a seguinte composição dos grupos: Grupo 1 com 160 registros, os quais, em grande parte, não apresentam informações sobre o e-mail do autor e área(s) do conhecimento; Grupo 2 com 301 registros, nos quais faltam, em sua maioria, o e-mail do autor, item por nós considerado importante conforme mencionado anteriormente; e por fim Grupo 3 com 193 registros, todos com informações completas.

Vale marcar que tal classificação se deu por entendermos que a ausência de uma ou mais informações básicas em um registro, tanto dificulta seu adequado entendimento por parte do usuário como torna difícil seu emprego em um trabalho aos moldes do nosso ou até mesmo a localização de um determinado trabalho para consulta. Entendemos também que a inconsistência do aspecto formal dos registros compromete, de certo modo, a qualidade das informações do BTC Resumos.

Ao apreciarmos os registros de dissertações da área da Educação, 158 no total, notamos que 117 (74\%) não apresentam o endereço do correio eletrônico, sendo que os 41 restantes (26\%) informam o e-mail do autor. Acerca dos volumes do trabalho de dissertação depositados na biblioteca da IES ou do programa de pós-graduação, constatamos que 141 registros $(89 \%)$ indicam o depósito de um único volume e $17(11 \%)$ indicam que disponibilizaram mais de um exemplar do trabalho.

No que tange à informação Agência(s) financiadora do autor, verificamos que 66 trabalhos (42\%) apresentam-se como financiados. Desse total, 40 indicam financiamento oferecido pela CAPES, 19 pelo CNPq e 7 por outras agências financiadoras. Os 92 registros restantes, os quais correspondem a 58\% do total, informam que não receberam financiamento.

Ao levantarmos os anos de defesa das dissertações, tendo em vista o seu ordenamento por Período de Desenvolvimento, constatamos que, no PD1, 21 trabalhos foram defendidos, enquanto, no PD2, houve um modesto aumento para 31 trabalhos. No PD3, com 106 dissertações defendidas, repetiu-se o resultado obtido com os levantamentos anteriores, isto é, houve um crescimento numérico considerável de trabalhos.

Coletamos também, excepcionalmente, assim como fizemos com as teses vinculadas à área da Educação, informações sobre a constituição de gênero dos autores dos trabalhos. Como resultado, obtivemos os seguintes números: 117 dissertações (74\%) foram desenvolvi-

2. Por informações completas, entendem-se: registro do nome do autor e título da dissertação; data da defesa; quantidade de volumes e páginas do trabalho; indicação do nível (mestrado); nome da IES e programa; nome do orientador; biblioteca depositária; e-maildo autor; palavras-chave; área(s) do conhecimento; banca examinadora; linha(s) de pesquisa; idioma; e dependência administrativa. 
das por mulheres e 41 por homens (26\%). Manteve-se, portanto, a presença majoritária de pesquisadoras mulheres nessa área, embora a disparidade seja um pouco menor do que a observada nas teses de doutorado.

\section{Aspecto formal dos resumos das teses}

Para analisarmos o aspecto formal dos 139 resumos de teses e 654 de dissertações, elegemos os seguintes critérios: extensão do resumo, formatação do texto (tipo de letra, fonte - seu tamanho e estilo -, número de parágrafos e alinhamento) e linguagem escrita. A escolha desses critérios se deu por entendermos que a variação constante da formatação do texto ou da extensão dos resumos - ora curtos, ora muito extensos ou, ainda, a presença de erros ortográficos ou de digitação, porque comprometem a apresentação estética das informações do resumo - não atendem à normalização científica e dificultam o entendimento adequado de seu conteúdo.

Antes de iniciarmos a análise do aspecto formal dos resumos, convém apresentar os critérios de algumas produções que versam sobre normas e regras para apresentação de teses e dissertações. Consultamos, primeiramente, a Norma 6028 da ABNT (2003), na qual consta que os resumos de trabalhos acadêmicos, tais como teses e dissertações, devem ter de 150 a 500 palavras. Não especifica, todavia, a quantidade de caracteres equivalente a esse número de palavras e se refere, de modo sucinto, à questão da formatação do texto.

Curty, Cruz e Mendes (2002), também de forma breve, recomendam apenas que o resumo não deve ultrapassar 500 palavras. Já o Programa de Pós-Graduação da PUC-RJ disponibiliza um manual de normas para apresentação de teses e dissertações, no qual frisa que "em teses o resumo deve ser apresentado com o máximo de 500 palavras e em dissertações e demais trabalhos acadêmicos, com o máximo de 250 palavras" (PUC-R10, 2006).
Severino (2002), por sua vez, destaca que "o texto do Resumo deve ser composto de um único parágrafo, com uma extensão entre 200 e 250 palavras, ou seja, de 1400 a 1700 caracteres, computando-se todos os seus elementos"; ademais, ressalta que a formatação do texto "[...] fica a critério dos organizadores e na dependência do tipo de publicação em que os Resumos serão divulgados” (p. 173-174).

Diante dessas variações de regras quanto à extensão dos resumos de teses e dissertações, optamos em não classificá-los de forma rígida, mas observar se os resumos apresentados são muito extensos ou curtos em demasia.

Da consulta efetuada nos resumos de teses, observamos que poucos são aqueles que contêm aproximadamente 500 palavras, conforme indicam as normas da ABNT (2003) e da PUC-RJ (2006). A maior parte deles apresenta uma extensão de mais ou menos 150 palavras, mas há também alguns que ultrapassam, e muito, o limite de 500 palavras. Registramos que o menor resumo verificado foi um de 81 palavras (ou 484 caracteres) e o mais extenso foi um de mais de 1.000 palavras (ou 6.300 caracteres). Encontramos, ainda, três registros sem resumo.

Referente à formatação do texto, constatamos que há uma padronização quanto à fonte empregada, seu tamanho e estilo, ao número de parágrafos e ao alinhamento. Em todos os resumos essa padronização corresponde a: fonte Arial; tamanho 8,5; estilo Normal; parágrafo Único; alinhamento do parágrafo $\dot{A}$ esquerda. Constatamos ainda, quanto ao tipo de letra, que grande parte dos resumos são apresentados com letra maiúscula/minúscula, embora existam também aqueles que apresentam todo o resumo em letra caixa alta, destoando do padrão.

Verificamos, em relação à linguagem escrita, não sem inquietação, que quase todos os resumos trazem algum tipo de erro no uso da língua portuguesa. A título de exemplo, vale registrar alguns dos problemas de linguagem observados, a começar pelas palavras ou expressões grafadas incorreta ou equivocadamente, tais como: "socioistorico"; "Consedera"; "terian"; "repeito"; 
"relaçõo"; "enfatisan”; “étinico”; “cosntatação”; "Educasão Matemaffca”; "affvidades"; "parse” (parte); "transforrnação” (transformação); "apolo" (apoio); "pare” (para); "narraffva” (narrativa); "idéais" (talvez ideais ou idéias); "na quilo" (naquilo); "o senso comu em emerge"; "acerditavam" (acreditavam); "peocesso” (processo); "independantemente"; "conse-guiram"; "seres hu- que sempre vivi" (seres humanos que sempre viveram?); "priemiro" (primeiro); "cosntatou-se"; "socieddae", entre outras.

Um outro problema de linguagem, freqüentemente presente, refere-se à acentuação, tanto empregada incorretamente como totalmente ausente em determinados casos. Alguns exemplos disso são: "tambem”; "ultimos”; “municipio”; "reaçào"; "amerindios”; "aparencia”; "existencia”; "Amazonia”; "definicão”. Problemas de concordância também se fazem presentes como, por exemplo, em "[...] a adolescentes deficientes vivencia [...]”. Há ainda palavras com letras faltando ou sobrando, por exemplo: "Esse alunos"; “compreeensão" etc.

Face a essas constatações, algumas indagações se impõem. Primeiramente, é possivel se cumprir, com efetividade, o papel designado a um banco de dados diante desses e tantos outros problemas? 0 que tais resultados relativos ao aspecto formal dos resumos de teses podem nos revelar? 0 que podemos pensar, frente à verificação de incorreções alarmantes, acerca do comprometimento do pesquisador, doutor, com o desenvolvimento do conhecimento científico e social, considerando que o BTC Resumos é, de certa forma, um meio de se fomentar a pesquisa científica e, por conseguinte, o desenvolvimento nacional?

É preciso considerar, por fim, que o zelo com a linguagem escrita é um requisito imprescindível a todo e qualquer texto, sobretudo o acadêmico, o qual, consensualmente, requer muito cuidado e atenção independente da área do conhecimento. Por conta disso, entendemos não ser necessário, nesta etapa da nossa análise, dar um tratamento à parte aos registros da área da Educação, os quais estão contempla- dos juntamente com os registros das demais áreas nos parágrafos ora expostos.

\section{Aspecto formal dos resumos das dissertações}

No que concerne aos 654 resumos de dissertações, observamos, de forma semelhante às teses, uma permanência das incorreções em seu aspecto formal. Verificamos, primeiro, uma variação considerável na extensão dos resumos, ora extremamente curtos como, por exemplo, um registro que apresenta um pequeníssimo resumo de 27 palavras ou 156 caracteres; outras vezes demasiadamente extensos, como ocorre com um dos registros cujo resumo contém 2.022 palavras ou 10.679 caracteres. Embora existam outros exemplos de resumos longos ou muito curtos e, até mesmo, dois exemplos de registros sem resumos, importa salientar que uma parcela considerável de registros apresenta resumos com uma extensão que se situa no meio termo, de 150 a 500 palavras, de acordo com a ABNT (2003).

Ao observar a formatação do texto, constatamos a mesma padronização adotada para os resumos das teses, qual seja, fonte Arial; tamanho da fonte 8,5 ; parágrafo Único e alinhamento do parágrafo À esquerda. Constatamos também que há muitos resumos apresentados com letra caixa alta (maiúscula), logo fora do padrão de letra minúscula/maiúscula seguido pela maioria dos registros.

Referente à linguagem escrita, observamos, mais uma vez, a presença de erro no uso da língua portuguesa. Para se ter noção de tais erros, vale citar alguns casos, iniciando pela questão da grafia errônea de algumas palavras como: "bemambiental” (bem ambiental); "objetoi” (objeto); "riquesa” (riqueza); "nao cobranca d acces" (não cobrança de ações); "delinguencia” (delinqüência); "traba lhadores”; "ultimas decadas da seculo XVIII"; "ersultados" (resultados); "simiestruturada” (semi-estruturada); "nu’tos” (mitos); "rtelações” (relações); "psíqueico" (psíquico); "sore" (sobre); "constituíse" (constituísse); "aritudes" (atitudes); "spectos" (aspectos).

Há ainda palavras escritas sem o devido 
espaçamento, exemplo: "Objetivandoaveriguaro [...]”; "dasciencias"; "hámuitas"; como também alguns casos de resumo que, repentinamente, são interrompidos, deixando o leitor sem conhecer o seu conteúdo na íntegra: "[...] omitida sua historia con".

Relativo à acentuação, equivocada ou ausente, convém marcar alguns exemplos: "assitencia"; "opinioes"; insatisfatoria”; "atraves"; "simbolicas"; "condiçòes"; "entao"; "razoes"; esteticos"; "historicos”. Vale destacar que vários resumos são apresentados, em sua íntegra, sem nenhum tipo de acento, enquanto outros não exibem a pontuação básica, como o ponto final, o qual é necessário para indicar ao leitor a finalização do texto. Incoerências de concordância também se fizeram presentes em alguns resumos.

\section{Resumos de teses e dissertações: definições e classificação}

Para expor uma outra ação empreendida com os resumos incluídos no banco de dados da Capes, ação essa que demarca uma segunda etapa do nosso trabalho, é preciso antes trazer à cena alguns subsídios sobre o que é resumo e qual o conteúdo que deve constituí-lo.

De acordo com a Norma 6028 da ABNT (2003), o resumo consiste em "apresentação concisa dos pontos relevantes de um documento [...]”, cujo conteúdo “[...] deve ressaltar o objetivo, o método, os resultados e as conclusões do documento". Consta também que, a depender do tipo de resumo - informativo ou indicativo - e o tratamento recebido no interior do documento original, a ordem e a extensão desses itens podem variar.

0 resumo indicativo é definido como aquele que "indica apenas os pontos principais do documento, não apresentando dados qualitativos, quantitativos etc. De modo geral, não dispensa a consulta ao original" (ABNT, 2003). Já o resumo informativo, como o próprio nome sugere, "informa ao leitor finalidades, metodologia, resultados e conclusões do documento, de tal forma que esta possa, inclusive, dispensar a consulta ao original" (ABNT, 2003).

Sem especificar as particularidades das modalidades de resumos como faz a ABNT, Curty, Cruz e Mendes (2002) destacam que o resumo

[...] põe em evidência os elementos mais importantes do conteúdo, visando fornecer, dessa forma, elementos para o leitor decidir sobre a conveniência ou não de consultar o texto completo. (p. 12)

Medeiros (2000), por sua vez, define resumo como "[...] um tipo de redação informativo-referencial que se ocupa de reduzir um texto a suas idéias principais" (p. 107). Menciona ainda que "para o pesquisador, o resumo é um instrumento de trabalho [...]" e que constitui numa "[...] apresentação sintética e seletiva das idéias de um texto, ressaltando a progressão e articulação delas” (p. 123).

Quanto ao conteúdo do resumo, Medeiros (2000) ressalta a importância de se destacar o assunto e o objetivo do texto, a articulação das idéias e as conclusões do autor. Quanto à forma, destaca que o resumo deve contemplar uma linguagem objetiva e evitar a reprodução de frases integrais do texto original, bem como obedecer à ordenação das idéias e dos fatos apresentados.

No manual de normas para apresentação de teses de autoria da PUC-RJ (2006), além da definição de resumo como "apresentação concisa de pontos relevantes do conteúdo e das conclusões do trabalho", há a definição de normas para a sua estruturação, entre elas: redação na terceira pessoa do singular com o verbo na voz ativa; composição seqüencial de frases e não enumeração de tópicos; o não emprego de fórmulas, equações, símbolos etc.; e a não inclusão de citações bibliográficas. Especifica, ainda, que "a primeira frase do resumo deve expressar o assunto tratado, caso o título do trabalho não seja explícito, situandoo no tempo e no espaço, ressaltando os objetivos, os métodos, os resultados e as conclusões do trabalho". 
Severino (2002), cuja publicação encontra-se na $22^{a}$ edição, explica que o resumo técnico de trabalho científico, entenda-se livro, artigo, dissertação, tese etc., caracteriza-se por uma apresentação breve de seu conteúdo e que tem por finalidade:

[...] passar ao leitor uma idéia completa do teor do documento analisado, fornecendo além dos dados bibliográficos do documento, todas as informações necessárias para que o leitor/pesquisador possa fazer uma primeira avaliação do texto analisado e dar-se conta de suas eventuais contribuições, justificando a consulta do texto integral. (p. 173)

Sobre o conteúdo que deve ser contemplado no resumo de trabalhos científicos, Severino (2002) ressalta que:

Atendo-se à idéia central do trabalho, o Resumo deve começar informando qual a natureza do trabalho, indicar o objeto tratado, os objetivos visados, as referências teóricas de apoio, os procedimentos metodológicos adotados e as conclusões/resultados a que se chegou no texto. (p. 173; grifo nosso)

Mediante essas informações, é preciso retomar e analisar o que anunciamos no parágrafo de abertura deste tópico, sobre o outro procedimento adotado nos registros do $B T C$ Resumos. Tal procedimento consiste, primeiro, na classificação geral dos resumos de teses e dissertações quanto ao objeto pesquisado e, segundo, no exame da estrutura dos resumos da área da Educação que abordam, efetivamente, o assunto preconceito.

Para realizar o primeiro procedimento, partimos de uma leitura seqüencial dos registros de teses e dissertações, na qual buscamos identificar, observando os itens título, palavraschave e conteúdo dos resumos, eleitos como critérios para nossa classificação, os registros que se referiam diretamente ou faziam alguma referência indireta ao assunto preconceito, por se tratar do nosso objeto de pesquisa.

Ao considerar o anúncio do título, bem como as expressões das palavras-chave e, sobretudo, a relação do conteúdo dos resumos com o assunto preconceito, classificamos os registros em $\mathrm{D}$, diretamente relacionado ao assunto preconceito, e $\mathbf{l}$, indiretamente ligado ao preconceito. Tal classificação, vale lembrar, teve como propósito mapear, sumariamente, a produção científica registrada no BTC Resumos acerca do fenômeno preconceito.

Em relação às 139 teses, identificamos e classificamos 21 registros como D e 116 registros como l, ficando três sem classificação pelo fato de não apresentarem resumos. Identificamos também que, dentre esses 21 registros classificados como $D$, somente seis eram da área da Educação e que, do universo dos 116 registros identificados como l, 25 pertenciam à área.

No caso das 654 dissertações, obtivemos como resultado da classificação os seguintes números: $\mathrm{D}=115$ registros, $\mathbf{l}=537$ registros e, novamente, 2 registros (sem resumos) não classificados. Dos 115 registros diretamente ligados ao preconceito, 37 deles eram da área da Educação, ao passo que, dos 537 indiretamente ligados, 121 se tratavam de registros dessa área.

Em linhas gerais, constatamos que os registros classificados como diretamente ligados ao preconceito focalizam as mais diversas questões, entre as quais, algumas são marcadamente reincidentes, tais como: preconceito de gênero, étnico, de idade, em relação a pessoas portadoras da síndrome da imunodeficiência adquirida (AIDS) ou do virus da imunodeficiência humana (HIV), em relação aos doentes de hanseníase, bem como preconceito lingüístico.

Quanto aos registros classificados como indiretamente ligados, verificamos que alguns resumos empregam, de modo esvaziado, a expressão preconceito, como se fosse uma palavra a mais no corpo do resumo, não deixando explícito seu real significado. Há muitos casos em que o assunto preconceito emerge de modo 
casual, decorrente da discussão de um assunto qualquer; em outros, ele é destacado como um dos resultados obtidos do objeto investigado. Ambos os casos não focalizam, pois, o preconceito como objeto principal da pesquisa, mas o trazem como um dos desdobramentos da investigação.

Acerca dos registros de teses e dissertações da área da Educação, classificados como diretamente ligados ao preconceito, constatamos que as abordagens gravitam em torno dos aspectos: preconceito escolar, em suas múltiplas dimensões; preconceito expresso nas relações sociais, especialmente em relação a pessoas negras, deficientes ou idosas; além de discussões sobre preconceito religioso e de profissionais da enfermagem. Em relação aos registros classificados como indiretamente ligados à temática em questão, repetiram-se as constatações explicitadas nos parágrafos acima.

\section{Explorando a estrutura de alguns resumos da area da Educação}

Mediante as inconstâncias verificadas no aspecto formal, tanto das informações básicas como dos resumos, e em concordância com a definição de Medeiros (2000) de que o resumo é um instrumento de trabalho do pesquisador, exploramos a estrutura dos resumos de teses $\mathrm{e}$ dissertações pertencentes, exclusivamente, à área da Educação e que têm como objeto de estudo o preconceito e suas interfaces (racismo, ações discriminatórias, segregação etc.).

Acerca dessa delimitação, é preciso marcar que ela se deve a dois fatores: pela impossibilidade, nesse momento, de submeter a um exame exploratório a totalidade dos resumos registrados no BTC Resumos, pelo fato de a Educação se tratar da nossa área de formação e atuação profissional e pelo fato de o tema preconceito ser um dos nossos focos de pesquisa. Esse segundo fator fundamenta o interesse em compulsar somente os resumos que abordam tal tema de modo efetivo, deixando à parte aqueles que se remetem ao preconceito devido discussão de um outro assunto qualquer, assim como aqueles que fazem referência ao preconceito como um dos resultados casualmente constatado do objeto pesquisado.

Ao empreendermos essa ação exploratória na estrutura dos resumos da área da Educação, os quais somam, entre os de teses e dissertações, o número de $43^{3}$, a fim de constatar o que é estudado, como é estudado e qual o resultado obtido, examinamos com cuidado o conteúdo de cada resumo. Para tanto, observamos a apresentação, com clareza ou não, dos seguintes aspectos: objeto estudado e problemas apresentados; objetivos da investigação realizada; metodologias e técnicas empregadas; referenciais escolhidos e teóricos adotados; resultados e conclusões.

Como o ato de examinar envolve apreciações prudentes do objeto escolhido e considerações ponderadas e fundamentadas, lançamos mão das questões abaixo, descritas por Severino (2002) a respeito do que deve conter um resumo, como apoio à ação exploratória proposta.

De que natureza é o trabalho analisado (pesquisa empírica, pesquisa teórica, levantamento documental, pesquisa histórica etc.)? Qual o objeto pesquisado/estudado? 0 que se pretende demonstrar ou constatar? Em que referências teóricas se apoiou o desenvolvimento do raciocínio? Mediante quais procedimentos técnico-operacionais se procedeu? Quais os resultados conseguidos em termos de atingimento dos objetivos propostos? (p. 173)

Antes de apresentar os resultados da ação exploratória, convém marcar que a realizamos presumindo as expectativas e necessidades dos pesquisadores, em especial os iniciantes, acerca dos dados fundamentais que precisam conter os resumos de teses e dissertações para que, de fato, lhes sirvam como instrumento de trabalho. Uma

3. Os 43 resumos da área da Educação foram submetidos a uma nova numeração, uma vez que a adotada até então se tornara inadequada. Para registros de teses de doutorado, atribuímos a numeração de 1 a 6 e, para os resumos de dissertação, a seqüência de 1 a 37. 
das expectativas/necessidades é, certamente, encontrar nos resumos uma adequada sistematização das idéias do trabalho completo, expectativa que se explica pela necessidade de se ter uma noção, ainda que elementar, das contribuições dos trabalhos já realizados para as pesquisas em desenvolvimento.

Em relação à estrutura dos resumos de teses de doutorado, constatamos, quanto ao aspecto objeto pesquisado, que este fica subentendido logo nas primeiras linhas dos resumos, não sendo, portanto, indicado por meio da expressão objeto de estudo ou expressão semelhante. Referente ao item problema, observamos que um único resumo, entre os seis examinados, apresenta tal item, já o objetivo é indicado em quatro resumos e omitido nos demais.

Em termos de informações sobre o tipo de pesquisa desenvolvida, constatamos que não há qualquer menção a esse respeito, ficando a cargo do leitor se aventurar, valendo-se do contexto que permeia o resumo na identificação do gênero da pesquisa realizada. Como não há referência direta ao tipo de pesquisa e "diretamente relacionados com o tipo de pesquisa serão os métodos e técnicas a serem adotados" (Severino, 2002, p. 162), não verificamos a indicação clara da metodologia empregada na maioria dos estudos.

Constatamos, sim, a indicação de técnicas de coleta de dados (presente em quase todos os resumos, com exceção de dois) como se fossem metodologias de pesquisa. Exemplo disso é o resumo identificado como número 1 , no qual é salientado que, para a defesa da tese levantada, "[...] foram realizadas pesquisas tendo como base a metodologia da História Oral, em duas vertentes: por um lado, história de vida e, por outro lado, a história temática" (grifo nosso). De acordo com Haguette (1999), em sua obra Metodologias qualitativas na Sociologia, tanto a história oral como a história de vida constituem-se em técnicas de captação de informações, as quais são empregadas em determinadas situações, não são, portanto, metodologias como consta no resumo de número 1 .
Quanto aos itens referencial teórico e teóricos, obtivemos o seguinte resultado: resumos que indicam tanto o referencial teórico como o(s) nome(s) do(s) teórico(s) que subsidia(m) o desenvolvimento do trabalho (1); resumos que indicam apenas o referencial utilizado (1); resumos que não apresentam ambas informações (4). Para os itens resultados e conclusão, verificamos: resumos que não apresentam tais itens (2); resumos que os apresentam (2); e resumos que apresentam apenas a conclusão, omitindo os resultados (2).

Em relação à estrutura dos resumos de dissertações, constatamos, quanto ao item objeto pesquisado, que tal aspecto fica subentendido na parte inicial de quase todos os resumos, assim como verificamos nas teses. Quanto ao item problema, em apenas seis resumos, ele se faz presente, logo, há 31 resumos que não contemplam tal aspecto. No que se refere ao(s) objetivo(s), observamos que eles são apresentados em 36 resumos, sendo omitido em apenas um deles.

0 item metodologia é mencionado em quatro resumos e omitido em 33. Quanto às técnicas de pesquisa, elas são mencionadas, ainda que de forma equivocada como se fossem metodologias de pesquisa, em 18 resumos e omitidas em 19 outros. 0 referencial teórico é constatado em apenas sete resumos e o item teóricos omitido em 36 e apresentado em um único resumo.

Acerca dos aspectos resultados e conclusão, verificamos que 20 resumos apresentam os resultados da pesquisa, ao passo que 17 não fazem essa indicação. Do total de 37 resumos examinados, 13 fazem menção das conclusões da pesquisa e 24 não.

Uma apreciação sumária do quadro explicitado nos permite reafirmar a importância de se evidenciarem, e de modo contextualizado, os itens objeto pesquisado e sua delimitação espacial e temporal; objetivos; procedimentos metodológicos, entendidos como metodologia da pesquisa e suas respectivas técnicas; além do referencial teórico subsidiário da pesquisa; resultado(s) alcançado(s) e conclusão. São itens fundamentais em um resumo, até mesmo para 
ser caracterizado como tal. Evidenciar todos esses aspectos possibilita, pois, ao pesquisador ter uma idéia do caminho enveredado por outros estudiosos, os enfoques dados e objetos contemplados, além de obter informações sobre perspectivas teóricas privilegiadas, entre outras informações imprescindíveis.

Ao se referir sobre o rigor exigido em trabalhos científicos em nível de pós-graduação stricto sensu, Severino (2002) assinala que "não há lugar, neste nível, para o espontaneísmo, para o diletantismo, para o senso comum e para a mediocridade" (p. 148). Nessa mesma esteira, complementamos, frente ao quadro exposto, que também não deve haver lugar, no mestrado e doutorado, para resumos malredigidos, confusos ou incompletos, enfim, mais ou menos informativo e formativo às avessas.

Assim, entendemos que é preciso que todos os resumos disponibilizados pelo BTC Resumos cumpram sua função de instrumento de trabalho do pesquisador e que não estejam ali registrados meramente para cumprir formalidades acadêmicas irrelevantes, haja vista que 0 pesquisador, ao recorrer a um banco de dados como o BTC Resumos, espera encontrar informações completas e precisas.

\section{Aspecto formal dos registros e estrutura de resumos do Banco de Teses CAPES, questões a serem exploradas?}

Diante do exposto e sem perder de vista o propósito deste ensaio, que é apresentar uma visão panorâmica dos registros incluídos no BTC Resumos, é preciso tecer algumas considerações. A primeira consiste em reiterar a relevância do banco de dados em tela como fonte de pesquisa, especialmente pelo seu caráter multidisciplinar e pela sua vasta abrangência, uma vez que abarca trabalhos de IES públicas e particulares de todo o território nacional e das mais diferentes áreas do conhecimento.

Exatamente por conta da relevância do Banco de Teses CAPES Resumos e das constatações feitas no decorrer da pesquisa é que convém marcar a importância de um maior cuidado com as informações contidas em sua base. lsso porque a gama de problemas constatados, tanto no que se refere ao aspecto formal das informações básicas e resumos como no que concerne à estruturação dos resumos da amostra que investigamos, suscita, ao nosso ver, um certo distanciamento do BTC Resumos quanto aos requisitos inerentes a um banco de dados.

Ao considerar que o papel atribuído a um banco de dados é disponibilizar informações completas, atualizadas e de fácil acesso e recuperação, entendemos que o não atendimento desses requisitos descaracteriza, de certo modo, a função que lhe é delegada, fato que pode redundar em sua banalização como banco de dados.

Avaliamos, portanto, que as IES e seus respectivos programas de pós-graduação devem zelar pelas informações incluídas no BTC Resumos. Por outro lado, há necessidade de que a CAPES estabeleça a condição mínima para que sejam publicados os resumos de dissertações e teses. Em última análise, consideramos que urgem investigações que contribuam para fomentar o debate sobre o tema, bem como auxiliar ações resolutivas, uma vez que o aspecto formal dos registros e a estrutura de resumos do Baco de Teses CAPES são, sim, questões a serem exploradas. 


\section{Referências bibliográficas}

ABNT. Associação Brasileira de Normas Técnicas. NBR 6028/2003: resumos. Rio de Janeiro: ABNT, 2003.

CAPES. Coordenação de Aperfeiçoamento de Pessoal de Nível Superior. Serviços: Banco de teses. 2005. Disponível em: <http:/ /servicos.capes.gov.br/capesdw/>. Acesso em: dez. 2005.

Conheça a CAPES: Histórico. 2006. Disponível em: <http://www.capes.gov.br/capes/portal/conteudo/10/historico.htm>. Acesso em: 19 jan. 2006.

CNPQ. Conselho Nacional de Desenvolvimento Científico E Tecnológico. Tabela de áreas do conhecimento. 2005. Disponível em: <http://www.cnpq.br/areas/tabconhecimento/index.htm>. Acesso em: 12 dez. 2005.

CURTY, M. G.; CRUZ, A. C.; MENDES, M. T. R. Apresentação de trabalhos acadêmicos, dissertações e teses (NBR 14724/ 2002). Maringá: Dental Press, 2002.

ECO, U. Como se faz uma tese. Trad. Gilson César Cardoso de Souza. 19. ed. São Paulo: Perspectiva, 2004.

HAGUETTE, T. M. F. Metodologias qualitativas na sociologia. 6. ed. Petrópolis: Vozes, 1999.

MEDEIROS, J. B. Redação científica: a prática de fichamentos, resumos, resenhas. 4. ed. São Paulo: Atlas, 2000.

PUC-RJ. Pontifícia Universidade Católica do Rio de Janeiro. Normas para apresentação de teses e dissertações. Rio de Janeiro: Coordenação Central de Pós-Graduação e Pesquisa. 2006. Disponivel em: <http://www.puc-rio.br/ensinopesq/ccpg/normas/ resumos_palavras_chave.html>. Acesso em: 21 jan. 2006.

SEVERINO, A. J. Metodologia do trabalho científico. 22. ed. São Paulo: Cortez, 2002.

Recebido em 18.07.06

Aprovado em 05.03.07

Renata de Almeida Vieira é graduada em Pedagogia pela Universidade Estadual de Maringá - UEM e bolsista PET/ SESu.

Lizete Shizue Bomura Maciel é doutora em Educação pela Pontifícia Universidade Católica de São Paulo - PUC-SP e docente do Departamento de Teoria e Prática da Educação e do Programa de Pós-Graduação em Educação da Universidade Estadual de Maringá - UEM. 